\title{
Influence of body mass index on Benign Prostatic Hyperplasia-related complications in patients undergoing prostatectomy
}

\author{
Hisham A Mosli ${ }^{1 *}$ and Hala H Mosli
}

\begin{abstract}
Objectives: To examine the link between increased body mass index and benign prostatic hyperplasia (BPH) related complications, namely: acute urinary retention (AUR), Bladder stones and Bladder diverticula.

Material and methods: Patients: We reviewed the medical records of BPH patients who underwent prostatectomy over three years period from 2010-2012. Prostatectomy was either done in the gold standard transurethral resection of the prostate (TURP) or using green light laser selective photo-vaporization (PVP). Age, PSA, Prostate Volume (PV) as measured by ultrasonography, patients' weight \& height, BPH related complications mainly AUR, bladder stones, and bladder diverticula were all taken in account. The BMI was calculated as weight in $\mathrm{kg}$ divided by square height in meters. The BMI was divided in 4 categories according to WHO classification: underweight if BMl $\leq 18.50 \mathrm{~kg} / \mathrm{m} 2$; normal weight if BMl $=18.50-24.9 \mathrm{~kg} / \mathrm{m} 2$; overweight: BMl $\geq 25 \mathrm{~kg} / \mathrm{m} 2$; and obese BMl if $\geq 30 \mathrm{~kg} / \mathrm{m} 2$. Statistical analysis: done using the SPSS package version 16. Chi-square test was used for comparison between groups where $p$-value was considered significant if $<0.05$ and ANOVA test was used for comparison between multiple variables.
\end{abstract}

Results: 197 patients were included in this study, of those 95(48\%) underwent TURP and 102(52\%) underwent PVP. The two groups were found to be similar in mean age and PSA, and significantly different in prostate volume and operating room (O.R.) time.

Conclusions: Although the mean weight for patients undergoing prostatectomy in this study was in the overweight range, yet only 59/197(30\%) patients with increased BMI presented with AUR. In this particular cohort of patients undergoing prostatectomy there was no significant differences in the development of AUR, bladder stone and diverticulum formation between patients with increased BMI (overweight and obese) and those with normal BMI. Further studies are recommended to explore the influence of increased BMI on $\mathrm{BPH}$-related complications.

\section{Introduction}

Obesity has recently been declared to be associated with several urological diseases (Hammarsten et al. 1998). Central obesity and lack of physical exercise were placed among the top risk factors for the development of $\mathrm{BPH}$ (Hammarsten et al. 1998; Hammarsten \& Högstedt 1999; Hammarsten \& Högstedt 2001; Hammarsten \& Högstedt 2002; Hammarsten et al. 2009). It has been shown in the placebo arm of Reduce ${ }^{\circ}$ study that the prostatic growth is accelerated in overweight and obese

\footnotetext{
* Correspondence: hmosli@hotmail.com

'Department of Urology, King Abdulaziz University, PO Box 80215, Jeddah

21589, Saudi Arabia

Full list of author information is available at the end of the article
}

patients while in the treatment arm the response to treatment with 5-alpha reductase enzyme inhibitors was attenuated in those patients (Kaplan \& Wilson 2007; Muller et al. 2012). It is therefore assumed that increased BMI is linked to increased prostate sizes in patients undergoing surgical treatment namely prostatectomy and when examining the BPH-related complications such as retention of urine (AUR), bladder stone and diverticulum formation, we anticipated that these complications were higher in overweight and obese patients than in normal weight patients undergoing prostatectomy.
Springer

(c) 2013 Mosli and Mosli; licensee Springer. This is an open access article distributed under the terms of the Creative Commons Attribution License (http://creativecommons.org/licenses/by/2.0), which permits unrestricted use, distribution, and reproduction in any medium, provided the original work is properly cited. 


\section{Objectives}

The objective of this study was to examine the link between increased BMI and BPH related complications. Those complications examined were: AUR, Bladder stones and Bladder diverticula.

\section{Material and methods \\ Patients}

We reviewed the medical records of $\mathrm{BPH}$ patients who underwent prostatectomy over three years period from 2010-2012. Prostatectomy was either done in the gold standard transurethral resection of the prostate (TURP) or using green light laser selective photo-vaporization (PVP). Age, PSA, Prostate Volume (PV) as measured by ultrasonography, patients' weight \& height, $\mathrm{BPH}$ related complications mainly AUR, bladder stones, and bladder diverticulum were all taken in account. The BMI was calculated as weight in $\mathrm{kg} \div$ square height in meter. The BMI was divided in 4 categories according to WHO classification: underweight if BMI $\leq 18.50 \mathrm{~kg} / \mathrm{m} 2$; normal weight if $\mathrm{BMI}=18.50-24.9 \mathrm{~kg} / \mathrm{m} 2$; overweight: BMI $\geq 25 \mathrm{~kg} / \mathrm{m} 2$; and obese BMI if $\geq 30 \mathrm{~kg} / \mathrm{m} 2$. All participants signed an informed consent prior to inclusion in the study. The study was approved by the Institution's Unit of Biomedical Ethics- Research Committee.

Statistical Analysis: Was done using the SPSS package version 16. Chi-square test was used for comparison between groups where p-value was considered significant if $<0.05$ and ANOVA test was used for comparison between multiple variables.

\section{Results}

197 patients were included in this study, of those 95 (48\%) underwent TURP and 102(52\%) underwent PVP. The two groups were found to be matched in mean age and PSA, and significantly different in prostate volume and operating room (O.R.) time. The results are summarized in Tables 1, 2, 3, 4 and 5 . Further analysis showed that of the 95 patients undergoing TURP, 38 (40\%, 19.2\% of total study population) were in the underweight-normal BMI group, whereas 67 (60\%, 28.8\% of total study population) were in the overweight-obese BMI group. Of the 102 patients undergoing PVP, BMI data was available for 77 patients. Analysis of this data showed that $34(44.15 \%)$ were in the underweight-normal BMI group, and 43 (55.85\%) were in the overweight-obese BMI group.

\section{Discussion}

Evidence elicited from the current study did not demonstrate an increase in the risk of developing BPH-related complications with an increased BMI. No significant differences were noted in the development of AUR, bladder stone and diverticulum formation; between patients with increased BMI (overweight and obese) and those with normal BMI. A relationship between higher BMIs and elevated PSA, poorer uroflow, increased incidence of retention, and larger prostate volume were expected to be seen, however our study demonstrated a relationship that was NOT statistically significant.

The metabolic syndrome is common in Arabian Gulf countries especially Saudi Arabia. It comprises a number of disorders-including insulin resistance, hypertension and central abdominal obesity-that all act as risk factors for cardiovascular diseases. Accumulating evidence now exists to link urological diseases to the metabolic syndrome (Hammarsten et al. 1998). Most established aspects of the metabolic syndrome are primarily linked to benign prostatic hyperplasia $(\mathrm{BPH})$ and prostate cancer (Hammarsten et al. 1998; Hammarsten \& Högstedt 1999; Hammarsten \& Högstedt 2001; Hammarsten \& Högstedt 2002; Hammarsten et al. 2009). Fasting plasma insulin, in particular, was linked to $\mathrm{BPH}$ and all subtypes of prostate cancer namely: incidental, aggressive and lethal prostate cancer (Hammarsten \& Högstedt 2002). Medical treatment is thought to be less efficacious in obese patients with symptomatic

Table 1 Patients undergoing TURP, PVP grouped by BMI

\begin{tabular}{|c|c|c|c|c|c|c|c|}
\hline \multicolumn{2}{|c|}{ Procedure } & \multicolumn{4}{|c|}{ BMI } & \multirow[t]{2}{*}{ Total } & \multirow{2}{*}{$\begin{array}{c}\mathrm{X} 2 \\
\text { P-vale }\end{array}$} \\
\hline & & Underweight & Normal & Overweight & Obese & & \\
\hline \multirow{2}{*}{ TURP } & Count & 1 & 37 & 41 & 16 & 95 & \\
\hline & $\%$ & $1.1 \%$ & $38.9 \%$ & $43.2 \%$ & $16.8 \%$ & $100.0 \%$ & 10.447 \\
\hline \multirow{2}{*}{ PVP } & Count & 6 & 28 & 21 & 22 & 77 & \\
\hline & $\%$ & $7.8 \%$ & $36.4 \%$ & $27.3 \%$ & $28.6 \%$ & $100.0 \%$ & \\
\hline \multirow{2}{*}{ Total } & Count & 7 & 65 & 62 & 38 & 172 & $0.015^{*}$ \\
\hline & $\%$ & $4.1 \%$ & $37.8 \%$ & $36.0 \%$ & $22.1 \%$ & $100.0 \%$ & \\
\hline
\end{tabular}

*significant using chi-square test at 0.05 level. 
Table 2 Showing the similarities and differences between the study's prostatectomy groups

\begin{tabular}{lccccc}
\hline & Group & N & Mean & Std. Deviation & P-value \\
\hline \multirow{2}{*}{ Age } & TURP & 95 & 68.36 & 8.67 & 0.020 \\
\multirow{2}{*}{ O.R. time } & PVP & 121 & 71.24 & 9.07 & \\
\multirow{2}{*}{ Prostate volume } & TURP & 95 & 86.48 & 37.56 & $<0.0001$ \\
& PVP & 79 & 61.12 & 40.38 & \\
\multirow{2}{*}{ PSA } & TURP & 95 & 60.95 & 33.32 & $<0.0001$ \\
& PVP & 101 & 46.93 & 14.30 & \\
\hline Abbren & 94 & 9.17 & 39.00 & \multirow{2}{*}{262} \\
\hline
\end{tabular}

Abbreviations: TURP transurethral resection of the prostate, $P V P$ photo-selective vaporization of the prostate, O.R. operative room, PSA prostate specific antigen.

BPH than normal weight patients (Lee et al. 2011). Overall, the results of studies on urological aspects of the metabolic syndrome seem to indicate that $\mathrm{BPH}$ and prostate cancer are recently considered as two aspects of the metabolic syndrome, and that an increased insulin level is a common underlying aberration that promotes both $\mathrm{BPH}$ and clinical prostate cancer (Nandeesha et al. 2006).

Affluence associated with prosperity in wealthy countries has resulted in some serious health problems due to overindulgence in the consumption of high calorie foods and sugar sweetened beverages, and intake of excessive amounts of fast and fatty food. Obesity follows with all its sequences, especially when living a sedentary life and lack of protective regular physical activities against cardiovascular diseases (Guo et al. 2005).

The main concern with the metabolic syndrome is the cardiovascular diseases, mainly coronary artery disease (CAD) as this is a leading cause of death. Furthermore, an association between benign prostatic hyperplasia and primary hypertension was reported (Guo et al. 2005). The relationships between body mass index and lower urinary tract symptoms (LUTS) were also reported.

Table 3 Shows the BMI categories of the study population

\begin{tabular}{llcc}
\hline & & Frequency & Percent \\
\hline & Underweight & 7 & 4.06 \\
& Normal & 65 & 37.79 \\
& Overweight & 62 & 36.04 \\
& Obese & 38 & 22.09 \\
& Sub-total & 172 & 87.30 \\
Data & Not available & 25 & 12.69 \\
Total & & 197 & 100.0 \\
\hline
\end{tabular}

Table 4 Showing the data for the whole cohort

\begin{tabular}{lll}
\hline Age & Minimum 51 & Mean 68.3684 years \\
& Maximum 90 years & standard deviation 8.67 \\
PSA & Minimum 00.00 & Mean $6.87 \mathrm{ng} / \mathrm{ml}$ \\
& Maximum 373.00 & standard deviation 27.57 \\
PV & Minimum 15 & Mean 54.11 \\
& Maximum 200 c.C. & standard deviation 26.52 c.C. \\
BMI & Minimum 16.8 & Mean $26.39 \mathrm{~kg} / \mathrm{m}^{2}$ \\
& Maximum 38.28 & overweight $>25 \mathrm{~kg} / \mathrm{m}^{2}$ \\
AUR & $74 / 197$ & $37.6 \%$ \\
Bladder stones & $17 / 180$ & $8.6 \%$ \\
Diverticulum & $3 / 194$ & $1.5 \%$ \\
\hline
\end{tabular}

Abbreviations: PSA prostate specific antigen, $P V$ prostate volume, $B M I$ body mass index, $A U R$ acute retention of urine.

The links of central obesity and lack of physical exercise to some medical conditions are all illustrated in Figure 1.

Obesity is measured by several methods, but for practical purposes and simplicity, it is represented in clinical urology by WC or BMI (Hammarsten \& Högstedt 1999). Recent data suggested a relationship between the WC and health parameters, mainly diabetes, hypertension, prostate volume (PV), voiding and sexual dysfunction (Hammarsten \& Högstedt 1999).Diabetes mellitus has been extensively discussed as a risk factor for many urological disorders, mainly voiding and sexual dysfunction (Ochiai et al. 2005; Li et al. 2005). Furthermore, there is evidence that type 2 diabetes mellitus is associated to, linked to, or even a direct sequel of obesity through the development of insulin resistance (Parsons et al. 2006). The resultant hyperinsulinemia (Parsons et al. 2009; Ozden et al. 2007; Keto et al. 2011; De Nunzio et al. 2012) plays a major role in the pathophysiological changes that occur in the genitourinary system and throughout the whole human body as shown in Figure 1.

Evidence from a large prospective study indicates that a progressive increase in the BMI is associated with progressive increase in $\mathrm{PV}$ and attenuated response to treatment with 5-alpha reductase inhibitors (Kaplan \& Wilson 2007; Muller et al. 2012; Lee et al. 2011; Roehrborn et al. 2006). In our opinion this finding has an important relevant therapeutic implication in the medical treatment of obese men with $\mathrm{BPH}$. This also warrants further research studies on the relationship between the degree of obesity and unresponsiveness to medical therapy and the development of complications of $\mathrm{BPH}$ such as retention of urine, bladder stones and diverticula formation. 
Table 5 Showing influence of BMI on BPH-related complications

\begin{tabular}{|c|c|c|c|c|c|c|c|c|c|c|c|}
\hline \multicolumn{3}{|l|}{ Group } & \multicolumn{2}{|c|}{ DIVERTICULUM } & \multirow{2}{*}{$\begin{array}{c}\text { Total } \\
38\end{array}$} & \multicolumn{2}{|c|}{ RETENTION } & \multirow{2}{*}{$\begin{array}{c}\text { Total } \\
38\end{array}$} & \multicolumn{2}{|c|}{ BLADDER STONE } & \multirow{2}{*}{$\begin{array}{c}\text { Total } \\
38\end{array}$} \\
\hline TURP & Normal & Count & $\begin{array}{c}\text { Absence } \\
37\end{array}$ & $\begin{array}{c}\text { Present } \\
1^{*}\end{array}$ & & $\begin{array}{c}\text { Absence } \\
22\end{array}$ & $\begin{array}{c}\text { Present } \\
16^{* *}\end{array}$ & & $\begin{array}{c}\text { Absence } \\
33\end{array}$ & $\begin{array}{c}\text { Present } \\
5^{* * *}\end{array}$ & \\
\hline & & $\%$ & $97.40 \%$ & $2.60 \%$ & $100.00 \%$ & $57.90 \%$ & $42.10 \%$ & $100.00 \%$ & $86.80 \%$ & $13.20 \%$ & $100.00 \%$ \\
\hline & Overweight \& Obese & Count & 55 & $2^{*}$ & 57 & 33 & $24^{* *}$ & 57 & 47 & $10^{* * *}$ & 57 \\
\hline & & $\%$ & $96.50 \%$ & $3.50 \%$ & $100.00 \%$ & $57.90 \%$ & $42.10 \%$ & $100.00 \%$ & $82.50 \%$ & $17.50 \%$ & $100.00 \%$ \\
\hline & & Count & 92 & 3 & 95 & 55 & 40 & 95 & 80 & 15 & 95 \\
\hline & & $\%$ & $96.80 \%$ & $3.20 \%$ & $100.00 \%$ & $57.90 \%$ & $42.10 \%$ & $100.00 \%$ & $84.20 \%$ & $15.80 \%$ & $100.00 \%$ \\
\hline \multirow[t]{6}{*}{ PVP } & Normal & Count & 28 & & 28 & 15 & $13^{* * * *}$ & 28 & 28 & $0 * * * *$ & 28 \\
\hline & & $\%$ & $100.00 \%$ & - & $100.00 \%$ & $53.60 \%$ & $46.40 \%$ & $100.00 \%$ & $100.00 \%$ & $0.00 \%$ & $100.00 \%$ \\
\hline & Overweight \& Obese & Count & 37 & & 37 & 31 & $6^{* * * *}$ & 37 & 36 & $1^{* * * * *}$ & 37 \\
\hline & & $\%$ & $100.00 \%$ & - & $100.00 \%$ & $83.80 \%$ & $16.20 \%$ & $100.00 \%$ & $97.30 \%$ & $2.70 \%$ & $100.00 \%$ \\
\hline & & Count & 65 & & 65 & 46 & 19 & 65 & 64 & 1 & 65 \\
\hline & & $\%$ & $100.00 \%$ & - & $100.00 \%$ & $70.80 \%$ & $29.20 \%$ & $100.00 \%$ & $98.50 \%$ & $1.50 \%$ & $100.00 \%$ \\
\hline
\end{tabular}

Abbreviations: TURP $=$ Transurethral resection of the prostate, $P V P=$ photo-selective vaporization of the prostate.

${ }^{*} P=0.50$.

** $P=0.66$.

*** $\mathrm{P}=0.50$.

$* * * *=0.45$.

***** $P=0.06$.

\section{Conclusions}

Although the mean weight for patients undergoing prostatectomy in this study was in the overweight range, yet only 59/197(30\%) patients with increased BMI presented with AUR. In this particular cohort of patients undergoing prostatectomy there was no significant differences in the development of AUR, bladder stone and diverticulum formation between patients with increased BMI (overweight and obese) and those with normal BMI. Further studies are recommended to explore the influence of increased BMI on BPH-related complications. Subsequently, active life style and weight reduction can be discussed with patients with symptomatic $\mathrm{BPH}$ within the context of benefit not only in improving LUTS, and slowing the growth of the prostate but also to improve response to medical therapy and prevent $\mathrm{BPH}$ related complications.

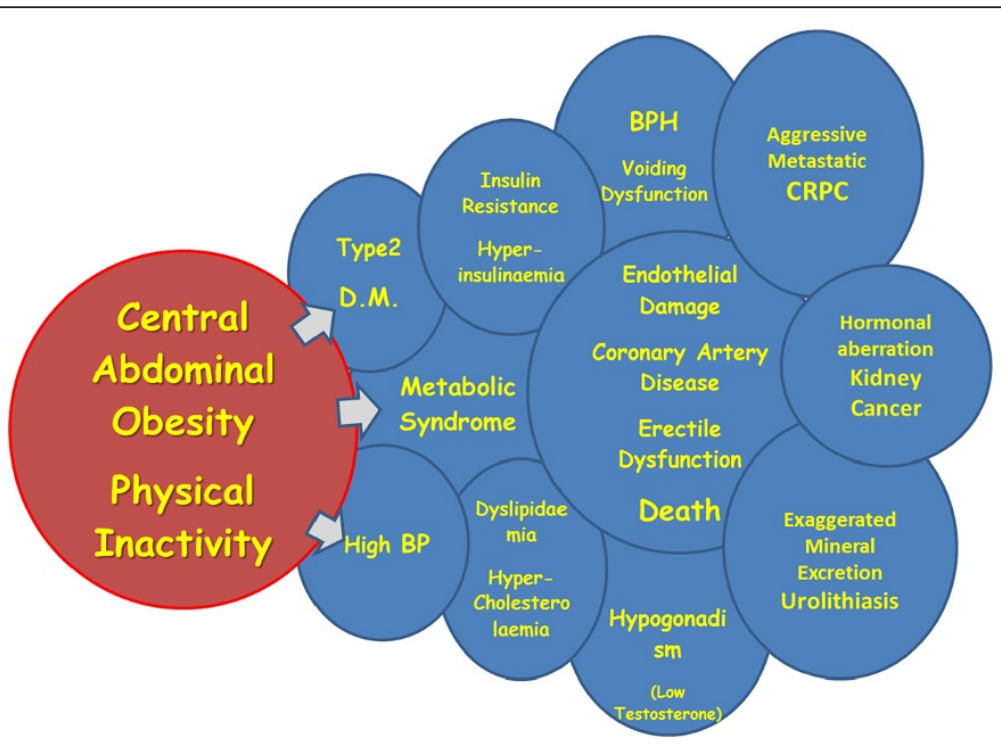

Figure 1 Illustrating the links between Obesity and affected health parameters. 


\section{Competing interests}

Nothing to declare, no funding received and no conflict of interests with the findings of this study.

\section{Authors' contributions}

HAM: Data collection, analysis and preparation of manuscript. HHM: Data analysis, preparation of manuscript. Both authors read and approved the final manuscript.

\section{Acknowledgments}

The authors would like to thank both Dr. Adel Assiry and Dr. Bandar AlHubaishy for their help in data collection.

\section{Author details}

'Department of Urology, King Abdulaziz University, PO Box 80215, Jeddah 21589, Saudi Arabia. ${ }^{2}$ Department of Medicine (Endocrinology), King Abdulaziz University, PO Box 80215, Jeddah 21589, Saudi Arabia.

Received: 5 June 2013 Accepted: 11 October 2013

Published: 17 October 2013

\section{References}

De Nunzio C, Aronson W, Freeland SJ et al (2012) The Correlation Between Metabolic Syndrome and Prostatic Diseases. Eur Urol 61:560-570

Guo LJ et al (2005) Association study between benign prostatic hyperplasia and primary hypertension. Zhonghua Wai Ke Za Zhi 43:108-111

Hammarsten J, Högstedt B (1999) Clinical, anthropometric, metabolic and insulin profile of men with fast annual growth rates of benign prostatic hyperplasia. Blood Press 8:29-36

Hammarsten J, Högstedt B (2001) Hyperinsulinemia as a risk factor for developing benign prostatic hyperplasia. Eur Urol 39:151-158

Hammarsten J, Högstedt B (2002) Calculated fast-growing benign prostatic hyperplasia-a risk factor for developing clinical prostate cancer. Scand J Urol Nephrol 36:330-338

Hammarsten J, Högstedt B, Holthuis N, Mellström D (1998) Components of the metabolic syndrome-risk factors for the development of benign prostatic hyperplasia. Prostate Cancer P D 1:157-162

Hammarsten J et al (2009) Insulin and free estradiol are independent risk factors for benign prostatic hyperplasia. Prostate Cancer P D 12:160-165

Kaplan S, Wilson TH (2007) Association between BPH and the metabolic syndrome in the REDUCE population. Program and abstracts of the American Urological Association 2007 Annual Meeting; May 19-24, 2007, Anaheim, California, Abstract 1548. J Urol 2007, Supplement 177, (4):511

Keto CJ, Maska EM, Freedland SJ (2011) Physical Activity, Obesity, and Lower Urinary Tract Symptoms. Eur Urol 60:1181-1183

Lee SH, Oh CY, Park KK et al (2011) Comparison of the clinical efficacy of medical treatment of symptomatic benign prostatic hyperplasia between normal and obese patients. Asian J Androl 13:728-731

Li PJ, Zhang XH, Guo L, Na YQ (2005) Correlation of benign prostatic hyperplasia with hyperlipemia. Zhonghua Wai Ke Za Zhi 43:387-389

Muller R, Gerber L, Moreira D et al (2012) Obesity is Associated with Increased Prostate Growth and Attenuated Prostate Volume Reduction by Dutasteride. Poster No.1736. AUA Annual Meeting, Atlanta, Georgia, USA

Nandeesha H, Koner BC, Dorairajan LN, Sen SK (2006) Hyperinsulinemia and dyslipidaemia in non-diabetic benign prostatic hyperplasia. Clin Chim Acta 370:89-93

Ochiai A, Fritsche HA, Babaian RJ (2005) Influence of anthropometric measurements, age, and prostate volume on prostate-specific antigen levels in men with a low risk of prostate cancer. Urology 66:819-823

Ozden C, Oxdal OL, Urgancioglu G et al (2007) The Correlation between Metabolic Syndrome and Prostatic Growth in Patients with Benign Prostatic Hyperplasia. Eur Urol 51:199-206
Parsons JK et al (2006) Metabolic factors associated with benign prostatic hyperplasia. J Clin Endocrinol Metab 91:2562-2568

Parsons JK, Sarma AV, McVary K et al (2009) Obesity and Benign Prostatic Hyperplasia: Clinical Connections, Emerging Etiological Paradigms and Future Directions. J Urol 182:S27-S31

Roehrborn C et al (2006) Baseline data from the Combination of Avodart and Tamsulosin (COMBAT) trial: relationships between body mass index and LUTS. BPH measures. Eur Urol Suppl 5:195

doi:10.1186/2193-1801-2-537

Cite this article as: Mosli and Mosli: Influence of body mass index on Benign Prostatic Hyperplasia-related complications in patients undergoing prostatectomy. SpringerPlus 2013 2:537.

\section{Submit your manuscript to a SpringerOpen ${ }^{\circ}$ journal and benefit from:}

- Convenient online submission

- Rigorous peer review

- Immediate publication on acceptance

- Open access: articles freely available online

- High visibility within the field

- Retaining the copyright to your article

Submit your next manuscript at $>$ springeropen.com 